\title{
Análisis de dos escaleras suspendidas de Arne Jacobsen
}

\author{
Analysis of two suspended staircases of Arne Jacobsen
}

A. Samper ${ }^{(*)}$, B. Herrera ${ }^{(*)}$

\section{RESUMEN}

En este trabajo analizamos dos escaleras suspendidas de la misma tipología estructural diseñadas por Arne Jacobsen: la escalera del Ayuntamiento de Rodovre y la escalera del Banco Nacional de Dinamarca. Ambas son parte primordial del vestíbulo principal de acceso en los edificios. Diseñadas con siete años de diferencia, presentan progreso técnico y estructural, manteniendo las mismas reglas de ordenación dentro del proyecto. Mostramos aquello que les da sentido y forma: expresión, función, técnica, posición, relación con otros elementos y sistema constructivo.

A partir de la escasa documentación original obtenida, elaboramos y presentamos nueva documentación con la que se pueden destacar los diferentes elementos. Con este trabajo, cualquier interesado en estas escaleras puede obtener todos los datos sobre ellas; datos que por diferentes motivos no se encontraban a disposición pública, hasta el presente artículo. Así, ponemos al alcance público otra fuente de ideas sobre la técnica y filosofía de Jacobsen.

$145-118$

Palabras clave: Ayuntamiento de Rodovre; Banco Nacional de Dinamarca; escaleras; Arne Jacobsen.

\section{SUMMARY}

In this paper we analyze two suspended staircases, with the same structural type, designed by Arne Jacobsen: the staircase of the Rodovre City Hall and the staircase of the Denmark National Bank. Both are essential part of the main access hall into buildings. They were designed with seven years of difference, they have technical progress, but they keep same management rules within the project.

We show what gives them meaning and shape: expression, function, technique, position, relationship with other elements and construction system.

From few original documents obtained, we have prepared and presented a new documentation, with that we can highlight the different elements. With this work, anyone interested in these staircases can get all the data about them; these data for various reasons were not publicly available, until the present paper.

Thus, we make available another public source of ideas about the technique and philosophy of Jacobsen.

Keywords: Rodovre City Hall; Denmark National Bank; staircases; Arne Jacobsen.

(*) Universitat Rovira i Virgili, Tarragona (España). 


\section{INTRODUCCIÓN}

A lo largo de la obra arquitectónica de Arne Jacobsen podemos encontrar tres escaleras colgadas: la escalera del Ayuntamiento de Rodovre en 1954, la escalera del Hotel Royal SAS en 1955 y la escalera del Banco Nacional de Dinamarca en 1961. El estudio de las mismas es importante a causa de la gran influencia de este autor como arquitecto e ingeniero industrial; sin embargo, no existe documentación pública, suficientemente precisa y técnica, al alcance de cualquier investigador interesado por motivo de la privacidad de uso de estos edificios. Generar esta información pública es el objetivo principal de nuestro trabajo. Por los parecidos técnicos y formales nos centramos en el análisis de la escalera del Ayuntamiento de Rodovre y la escalera del Banco Nacional de Dinamarca. La tercera escalera aludida merece un estudio aparte de las dos iniciales; esto es así por sus diferencias de diseño, estructura y composición.

En el guión de la presente investigación seguimos una pauta similar a la que se produce al Ilegar al edificio, acceder al vestíbulo principal, encarar la escalera y subir por ella. Unas secuencias que van definiendo pautadamente el significado global de este trabajo; con la suma de todos estos "pasos y miradas" se irán aclarando todas las decisiones que Arne Jacobsen tomó al diseñar estos elementos.

Este estudio no pretende explicar los edificios donde se hayan las escaleras, justo lo contrario, pretendemos explicar las escaleras mediante los espacios y los elementos del edificio que están proyectados entorno a ellas. Y pretendemos explicar la intención de cada uno de los gestos de estas escaleras hasta descubrir todas las capas que conforman el detalle constructivo. Por tanto presentamos aquí una manera nueva e inédita de explicar dos escaleras de la misma tipología estructural, de este arquitecto reconocido, situadas en dos vestíbulos formalmente muy distintos pero que se proyectan con las mismas reglas visuales, geométricas $\mathrm{y}$ formales.

Nuestro objetivo principal es descubrir cada detalle y material de estas escaleras que están proyectadas con unos cánones similares al resto del edificio. Pretendemos hacer una reconstrucción bidimensional y tridimendional tratando de aclarar documentación gráfica histórica que no describe con claridad estas dos escaleras. Y con todo, explicaremos la razón formal de diseñar unas escaleras suspendidas en estos espacios determinados.

\section{MATERIAL}

Para abarcar la investigación, la principal fuente de información han sido las revistas de época: Architecture d'aujourd d'hui (1), Informes de la Construcción (2), Casabella Continuità (3), Space Design (4), Architectural Record (5), Edilizia Moderna (6), COAM Arquitectura (7). Es en este registro donde se encuentra el mayor número de detalles gráficos, ya sea del proyecto o de las escaleras en particular.

Existe una gran variedad de monografías de Arne Jacobsen (8) (9) (10) (11) (12) (13) (14) (15) (16). Sin embargo, pocas son del nivel necesario para poder ser consideradas como punto de referencia en la presente investigación. La que más información ofrece, y en la cual se pueden apreciar los detalles más técnicos de los componentes de estudio, es la monografía de Clásicos del diseño de Arne Jacobsen (11).

En cuanto a la abundancia de información que ofrecen las fuentes de Internet, es preciso aclarar que debe ser contrastada. Además, en la mayoría de los casos, tal información ha de ser tratada posteriormente para mejorar el enfoque de los conceptos. Buscadores especializados como Google Scholar, la Biblioteca del COAC, el Catálogo de la UPC o la base de datos de la Royal Institute British Architects han sido las principales herramientas de indagación, por su rigurosidad en la información, su proximidad y facilidad de acceso.

\section{MÉTODO}

Para poder llevar a cabo la presente investigación, la cual requiere nuevos puntos de vista, hemos reelaborado todos los documentos originales con la rigurosidad necesaria para poder generar un nuevo documento. Éste está dotado de las cualidades oportunas para transmitir los rasgos de estudio. Este proceso de reconstrucción se ha hecho mediante la observación minuciosa de documentos gráficos, ya sean fotografías o planos técnicos. Posteriormente, su informatización se ha realizado a través de programas como el AutoCad, en el caso de hacer una reconstrucción bidimensional, y de Google Sketchup, en el caso de hacer una reconstrucción tridimensional.

El proceso empieza compilando la mejor información posible para disponer de una descripción exhaustiva que permita observar la globalidad del proyecto y afrontar el análisis. Seguimos con una posterior digitalización de calidad de todos los documentos, planos o fotografías. Los nuevos dibujos los hemos delineado guardando fidelidad al 
original pero con nuevos valores de trazos de dibujo, aportando el valor de línea y las tramas adecuadas para poner de relieve las circunstancias que hemos querido destacar.

Finalmente, este documento se ha modelado siguiendo estrictamente los planos redibujados; pero, con las eventuales modificaciones que necesariamente se extraen de fotografías reales de los elementos y visitas in situ. Esas fotografías y visitas exigen hacer las modificaciones oportunas a los planos para ajustarlos a la verdadera construcción final.

\section{CIRCUNSTANCIAS EN RODOVRE}

El ayuntamiento de Rodovre se emplaza en una expansión urbana desarrollada sobre un cinturón verde extendido entre el Lago Damhussoen y las fortificaciones de Vestvolden (Figura 1). Se preveía la construcción de otros edificios institucionales; pero, sólo se consumaron el ayuntamiento en 1954 y la biblioteca en 1969, ambos de Jacobsen, además del centro comunitario de Dissing\&Weitling en 1978. La falta del resto de edificaciones consumó un espacio excesivamente abierto para ser percibido como una plaza cívica. Sin embargo, las dimensiones del edificio del ayuntamiento $(14 \times 91$ en planta, $\mathrm{PB}+2)$ permiten que éste actúe eficazmente como articulación entre las zonas este y oeste de la ciudad. Su fachada oeste mira a la ciudad. Los testeros norte y sur permanecen ocultos tras alineaciones de árboles, creando un filtro visual y enmarcando el paso hacia el acceso al edificio. En contraste, la fachada este ofrece la imagen de un solitario volumen horizontal apoyado serenamente sobre el plano verde (8) (9) (10).

Siguiendo una característica frecuente en su obra, Jacobsen agrupa ortogonalmente los volúmenes, y a cada uno de los cuales les asigna funciones diferentes. El volumen mayor recoge el vestíbulo. Este ámbito está ligeramente escorado hacia la izquierda en medio de una planta dedicada a las zonas

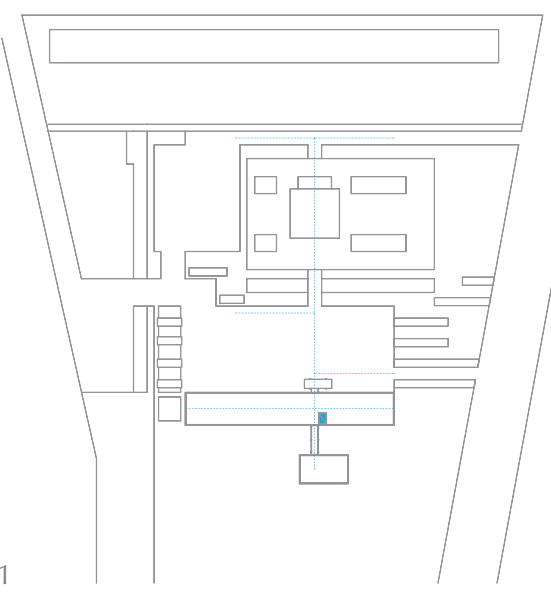

de trabajo. Atravesando ese espacio se encuentra un corredor vidriado de $13 \mathrm{~m}$ de longitud que conduce a la Sala del Concejo Municipal, cuya proporción ( 13 × 22,1 planta) se desprende de la sección áurea. La relación de dos cuerpos articulados por una pasarela se presenta en otras obras del maestro danés como: la Fábrica Novo en 1934, el St.Catherines's College en 1960, el proyecto para el Concurso de la OMS en 1960 y el Banco Nacional en 1961 (8) (9) (10).

Al margen de la cuidadosa elección de los materiales, Jacobsen produce una serie de diseños memorables para algunos detalles y elementos del mobiliario, entre ellos el de la escalera central. Situando la escalera en el plano de urbanización (Figura 1), nos damos cuenta que su posición se rige por unos ejes que cruzan la plaza central hasta llegar al acceso de la Biblioteca y se desvincula sutilmente hacia la derecha, desmarcándose y liberándose de esta tensión y orden basándose exclusivamente en lo visual.

\section{CIRCUNSTANCIAS EN COPENHAGUE}

En 1961, Arne Jacobsen ganó un concurso restringido para el diseño del edificio. El proyecto mantiene en su totalidad los aspectos que el arquitecto presentó al concurso con la excepción de la entrada original. La entrada, proyectada en la fachada norte, se ubicó definitivamente en la fachada opuesta por motivos de seguridad (Figura 2). Este cambio hizo que todo el edificio girase 180 grados. La primera fase concluyó en 1971 con la construcción de la imprenta y parte de las oficinas. Tras la muerte del arquitecto, el resto del edificio, la entrada y el cuerpo bajo, fue completado por sus colaboradores y socios, Hans Dissing y Otto Weitling. Esta fase concluyó en 1978 (8) (9) (10).

La vegetación tiene un papel importante en este proyecto. La cubierta de los patios y del cuerpo bajo aparecen como unas quintas fachadas permanentemente presentes en el edificio: jardines románticos diseñados

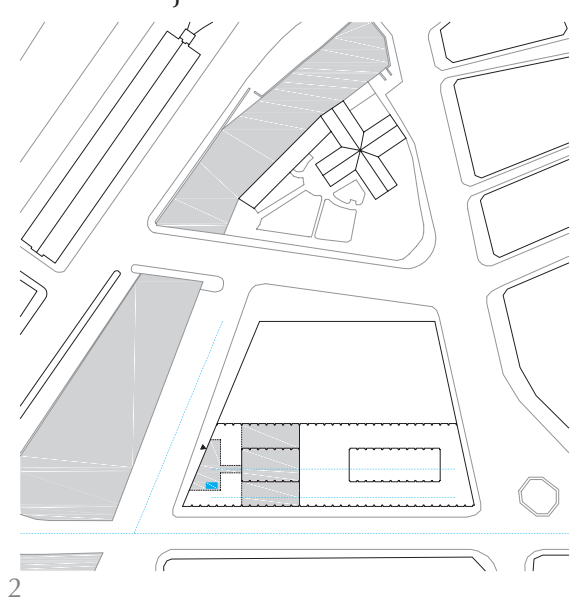

1. Emplazamiento del conjunto proyectado por Arne Jacobsen. Ayuntamiento y Biblioteca.

2. Emplazamiento urbano del Banco Nacional de Dinamarca haciendo referencia a dos de sus límites. La iglesia Holmens y el río. 
3. Planta de acceso al ayuntamiento indicando con sombreado los tres elementos que tienen una repercusión organizativa en el vestíbulo. con fustes de hormigón que asoman entre guijarros, piedras, rocas, plantas y arbustos de hoja perenne. En cambio, la cubierta del cuerpo bajo se asume como un plano que tiene continuidad en la zona ajardinada de la pequeña iglesia vecina. En la resolución del perímetro también se recurre a la vegetación. Una lámina de agua, un muro sinusoide y capiteles clásicos acompañan a una hilera de árboles recortados que rodean parte del conjunto y definen su verdadero límite, convirtiéndose en un zócalo verde que oculta la franja horizontal que separa el cuerpo alto del opaco basamento gris (8) (9) (10).

Una pequeña y discreta abertura en la fachada sur del muro perimetral es la entrada principal. Una vez atravesada la piel gris, se accede por una caja acristalada y curva, la cual se encuentra colgada del techo, al impresionante vestíbulo. Se trata de un espacio nebuloso iluminado por las hendiduras de la fachada, generando un ambiente gris que envuelve el discurrir de una escalera suspendida del oscuro y lejano techo.

Se vuelve a repetir la operación de situar la escalera en el plano de urbanización (Figura 2); y apreciamos que en este caso la escalera no es vinculante a ningún eje circunstancial, simplemente se sitúa en el proyecto rigiéndose al programa y a su presencia en el vestíbulo. La escalera, al ser de un edificio que está sumergido en un entorno urbano denso, sigue las reglas de su propio orden interno; y se desvincula de un eje imaginario que conecta el vestíbulo principal con la sala de imprenta.

\section{ESENCIA Y SECUENCIA DEL VESTÍBULO}

Arne Jacobsen utiliza diferentes recursos para indicar la entrada en sus edificios. En proyectos donde hay un retranqueo volu-

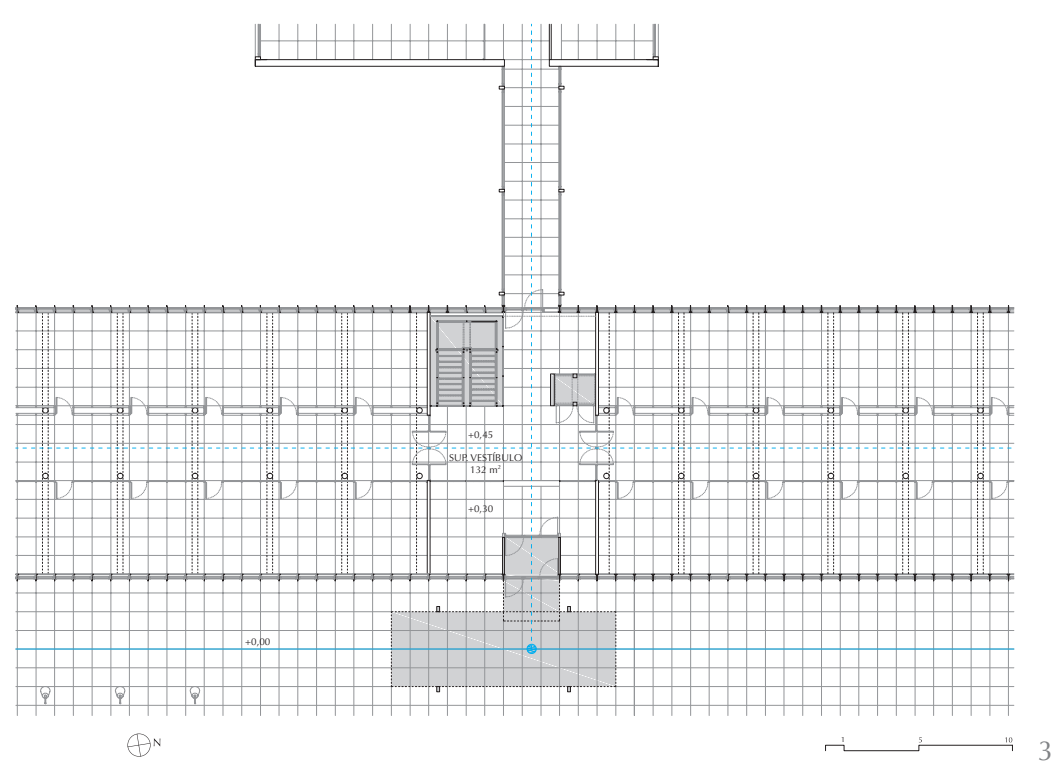

métricamente claro, es la propia geometría la que se encarga de señalar la zona de acceso; en cambio, en el caso del Ayuntamiento de Rodovre y el Banco Nacional de Dinamarca, donde la volumetría del edificio es rotunda y compacta, se diseña un elemento que sobresale de la rasante de la fachada y resguarda al visitante delante de la entrada inmediata al edificio. Este gesto magnifica el entorno urbano invadiendo la zona peatonal y hace que la llegada se produzca de forma paralela a la fachada principal. En el Ayuntamiento de Rodovre este recurso se produce mediante una doble marquesina a diferentes alturas y en el Banco Nacional se remarca mediante un alero de cristal con perfiles de acero. Estas dos piezas, de la misma manera que en las catedrales góticas, actúan a modo de atrio, siendo zonas de transición entre la escala espacial exterior y la escala espacial interior. Estos elementos marcan una relación directa con las escaleras a modo compositivo y a nivel formal, ya que definen los límites del vestíbulo, compartiendo rasgos comunes en el diseño estructural.

La secuencia de entrada al vestíbulo desde el exterior sucede de forma gradual en el caso de Rodovre, se pasa de estar en el exterior, a estar cubierto por una marquesina de 2,76 metros de altura. Luego, bajo otra marquesina colgada de la primera y de 2,20 metros de altura, se sube un peldaño de 15 centímetros. Seguidamente se atraviesa un cortaviento cuyo techo es la prolongación de la segunda marquesina, para finalmente aparecer en el vestíbulo, que con su altura, pretende recuperar metafóricamente la sensación espacial del exterior.

En el Banco Nacional esta secuencia es más directa. El recorrido del exterior al interior transcurre a través de una puerta de acero de proporciones cuadradas (lado 2,20 metros), conectada a un elemento vidriado colgado del techo, en forma de cuña y en rampa que baja 15 centímetros. Esta componente va canalizando la mirada a un vestíbulo de seis niveles libres, que se abre de nuevo simulando el espacio exterior. Es un cortaviento de acceso acotado y pesado que contrasta con un vestíbulo profundo y que se relaciona a nivel estructural con la escalera principal de estudio totalmente suspendida del techo.

El vestíbulo de Rodovre, de proporción áurea, se compone de tres elementos ( $\mathrm{Fi}$ gura 3): la pieza de acceso enfrentada al corredor que une el vestíbulo con la Sala Capitular, los ascensores y la escalera, siendo éstos últimos los que en paralelo se desmarcan del eje principal que pauta la entrada con el corredor. Estas piezas se si- 
túan a diferentes cotas ya que el vestíbulo se desdobla en dos planos debido a su distribución y diseño. En el primer plano del vestíbulo de forma rectangular y de altura libre 3,30 metros, encontramos el cortaviento y dos peldaños encarados a este elemento que conectan con el segundo plano. El nivel superior, cuadrangular, lo podemos subdividir en dos zonas según su función; el primer ámbito con una altura libre de 3 metros, está relacionado con los distintos despachos mediante un corredor longitudinal. Una segunda zona con una altura libre de 9,38 metros, donde encontramos los ascensores y la escalera, se ordena siguiendo la geometría del pavimento de mármol noruego de Gjellebaek, de proporciones cuadradas de $1 \times 1$ metros. Esta misma geometría se extiende en forma de malla al resto del edificio ordenando todo el proyecto (1) (2) (3) (5) (7).

A la izquierda y tangencialmente al corredor que conecta con la Sala Capitular se encuentra el elemento principal de estudio. La escalera de tipología lineal, está colgada por un extremo mediante tres tensores y apoyada a los diferentes niveles por el otro extremo. Este sistema estructural hace que la escalera no contacte físicamente con sus límites, excepto por el lado en el que se apoya, liberándola del orden estricto que pauta la maIla del pavimento. A la derecha y siguiendo la alineación de la escalera encontramos la caja de ascensores que, por su dimensión, invade la anchura del corredor y la del cortaviento. La escalera y la caja de ascensores están construidos con la mayor esbeltez y ligereza posible, siendo la intención, captar la máxima luz posible del exterior y dejar ver desde el vestíbulo el segundo volumen que conforma el proyecto, el que corresponde a la Sala Capitular. Por estos dos motivos, Arne Jacobsen diseña una escalera colgada, liberada de su perímetro y sin contrahuellas; son propiedades que tratan de favorecer la voluntad de diseñar una escalera con formas y materiales lo más ligeros y transparentes posibles. Con los mismos fines, la caja de ascensores está construida con vidrio y perfiles metálicos (1) (2) (3) (5) (7).

El vestíbulo del Banco (Figura 4) es de forma trapezoidal y su superficie dobla la del vestíbulo del Ayuntamiento. Formalmente se compone de dos elementos: el recinto de la entrada colgado del techo con tres tensores, y la escalera de servicio al edificio colgada del techo mediante ocho tensores. Estos elementos equidistan de un corredor situado perpendicularmente al vestíbulo que da salida a una sala de oficinas. Es una sala diáfana con lucernarios vegetales y con acabados de madera; contrasta con el vestíbulo principal el cual está protagonizado por una atmósfera intencionadamente

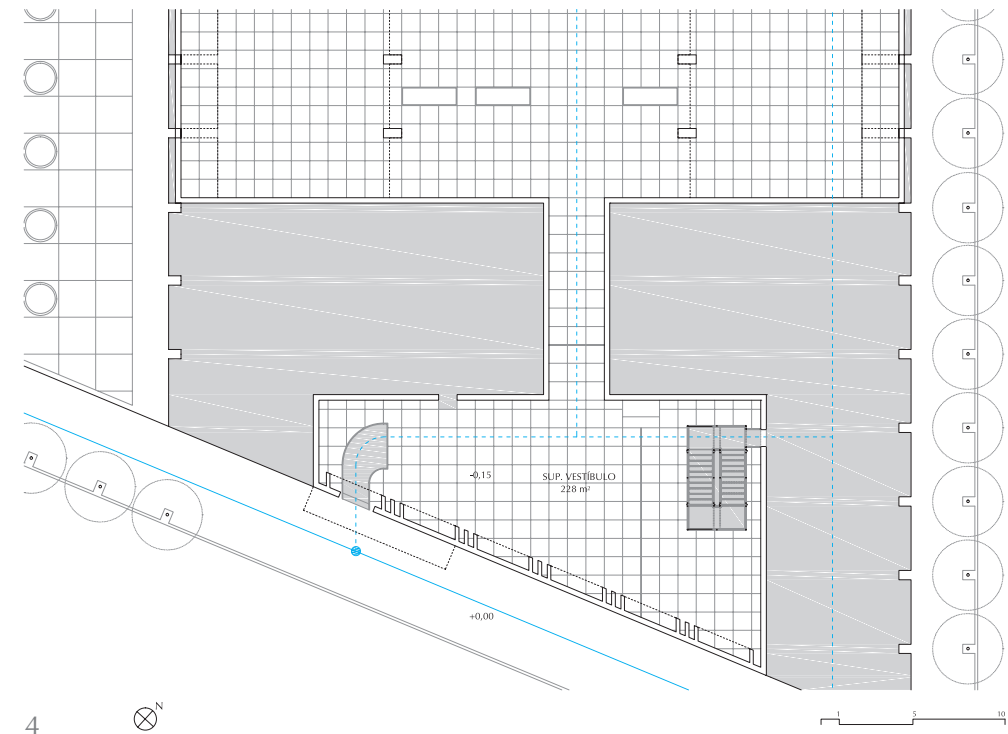

oscura y fría, donde el único síntoma de calidez es la luz natural que penetra por las rasgaduras verticales que hay entre los seis módulos de la fachada. De la misma manera que en el Ayuntamiento, la geometría del vestíbulo del Banco está pautada siguiendo la malla que genera el pavimento de dimensiones de $1 \times 1$ metros que a su vez se prolonga en todo el proyecto (4) (6) (13).

La escalera del Banco Nacional, de tipología lineal, está completamente colgada por ocho tensores y desvinculada de su perímetro. Su posición queda definida con la alineación del cortaviento y está sutilmente adelantada 75 centímetros del muro que hace de telón de fondo de todo el vestíbulo; es un muro de mármol de Porsgrunn. La conexión con los diferentes niveles se hace mediante una pasarela metálica de mínima sección, sin perder la esencia que buscaba Arne Jacobsen de ser un elemento espacialmente autónomo. Otra de las diferencias con la escalera del Ayuntamiento de Rodovre es su posición en relación a la visión que tiene el usuario al acceder al vestíbulo. En este caso, la escalera no se encuentra de frente, ya que su posición queda determinada por el lugar de procedencia de la fuente de luz. Luz que penetra a través de las aberturas verticales de la fachada, y el arquitecto coloca la escalera paralela a la dirección de la luz. Con los mismos propósitos que en el Ayuntamiento, esta escalera está diseñada sin contrahuellas para obstaculizar mínimamente el recorrido de la luz natural y acentuar el efecto liviano de todo el conjunto (4) (6).

Las conclusiones descritas anteriormente las hemos obtenido mediante documentos que hemos dibujado expresamente para este trabajo. Hemos contrastado ambas escaleras con estos documentos comparándolas en paralelo y con la misma escala gráfica para realzar las diferencias entre ambas. 
SECCIÓN FUGADA A-A ESCALA GRÁFICA

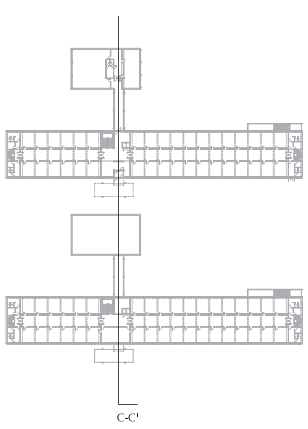

SECCIÓN FUGADA B-B ESCALA GRÁFICA

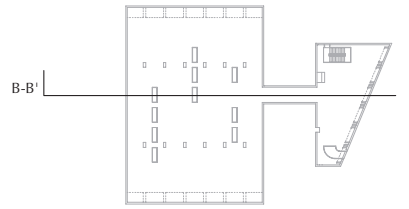

5. Sección fugada del Ayuntamiento de Rodovre por el eje central del vestíbulo proyectando la escalera.

Cota: El primer plano del vestíbulo a 30 centímetros por encima del nivel peatonal, y el segundo plano del vestíbulo a 45 centímetros del nivel peatonal. Superficie: 123 metros cuadrados. Altura libre: 3,30 metros de altura en el primer plano de acceso, 3 metros de altura en el segundo ámbito y 9,38 metros de altura libre en la zona de la escalera y el ascensor.

6. Sección fugada del Banco Nacional de Dinamarca por el eje central del vestíbulo proyectando la escalera.

Cota: 15 centímetros por debajo del nivel de la calle. Superficie: 228 metros cuadrados. Altura libre: 19,20 metros.
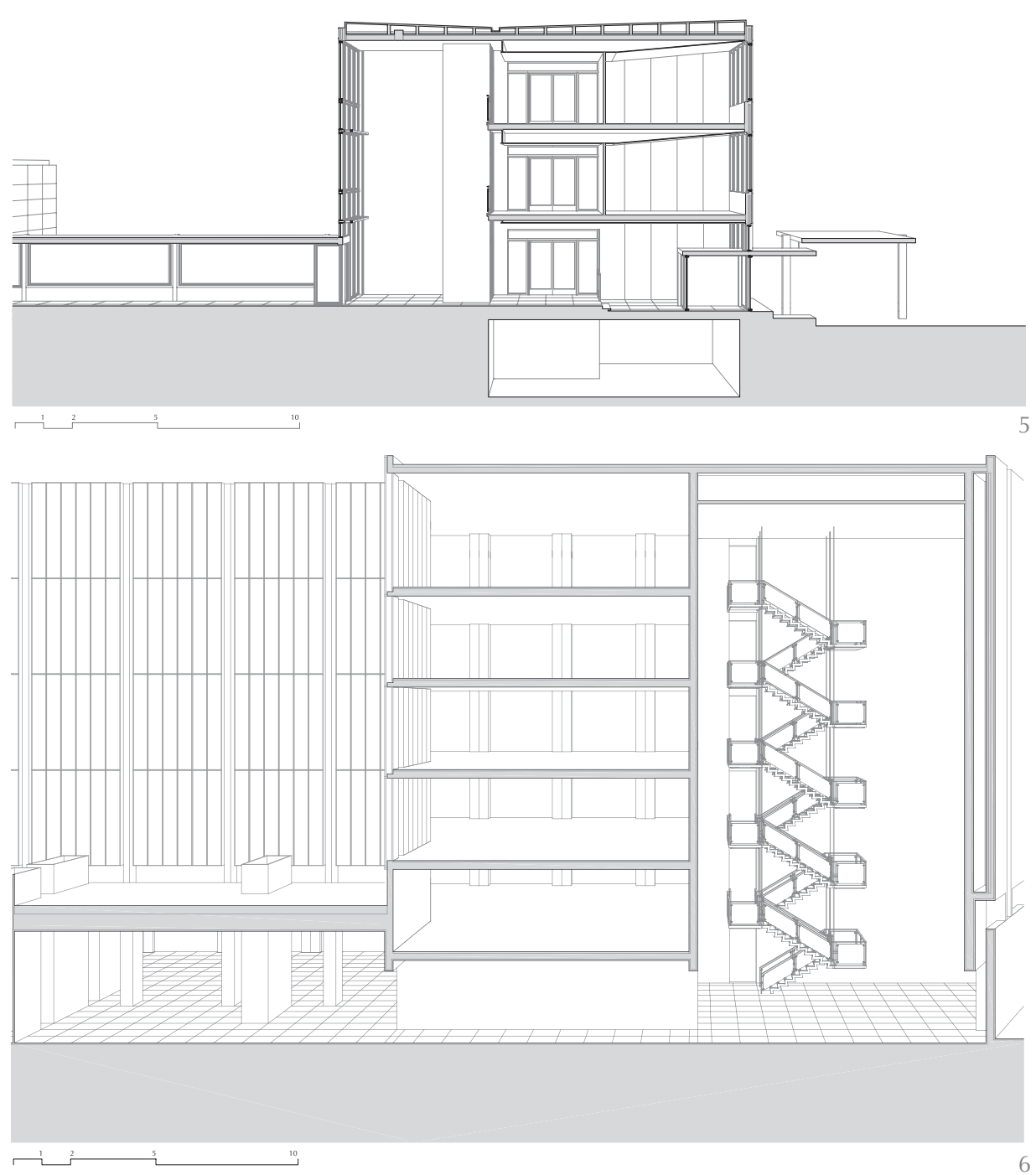

Hemos elaborado cuatro secciones verticales fugadas hechas por ambos corredores (Figuras 5, 6, 7 y 8). Dos de estas secciones proyectan las escaleras, las otras dos proyectan los accesos. Con este material explicamos gráficamente las relaciones programáticas que tienen los vestíbulos con el resto del edificio; y mostramos la concordancia formal y compositiva que tienen las escaleras en relación al vestíbulo cuando las vemos al entrar o al salir de estos espacios.

Estos documentos muestran la profundidad de los vestíbulos al ser secciones fugadas. La elaboración gráfica correspondiente al Banco Nacional de Dinamarca nos ha sido mucho más difícil que la del Ayuntamiento. En diferentes revistas de arquitectura de la época hemos encontrado múltiples detalles constructivos del ayuntamiento que nos han ayudado en la elaboración del trabajo; sin embargo, lo mismo no ha sido posible en el caso del banco. Esto es debido a que el Banco prohíbe la entrada al recinto al público, y a la limitación de la divulgación de material gráfico por motivos de seguridad. A pesar de esta escasez de información, existe una publicación realizada por el propio Banco
Nacional (14) que describe gráficamente algunas partes muy particulares del edificio. Entre estas partes encontramos: una sección horizontal de un detalle constructivo de uno de los seis módulos que forman la fachada del vestíbulo, un plano de emplazamiento y un esquema en planta y en sección del vestíbulo y la sala de oficinas. Con este material técnico y fotografías hemos podido reconstruir de forma muy precisa todos los gráficos que presentamos (4) (15).

Después de haber generado un modelo trilas cuatro secciones fugadas, hemos dibujado unas perspectivas interiores que ayudan a explicar los parámetros. Las premisas marcadas para este ensayo han sido realizar dos perspectivas frontales desde dos puntos de vista geométricamente opuestos: la primera vista entrando al vestíbulo del Ayuntamiento mirando la escalera, y la segunda desde el corredor mirando al acceso. En el caso del Ayuntamiento de Rodovre elaboramos las perspectivas mediante el modelo tridimensional, ya que no encontramos ninguna fotografía que se ajustara a las premisas geométricas establecidas (Figuras 9 y 10). dimensional de estos dos espacios y realizar 


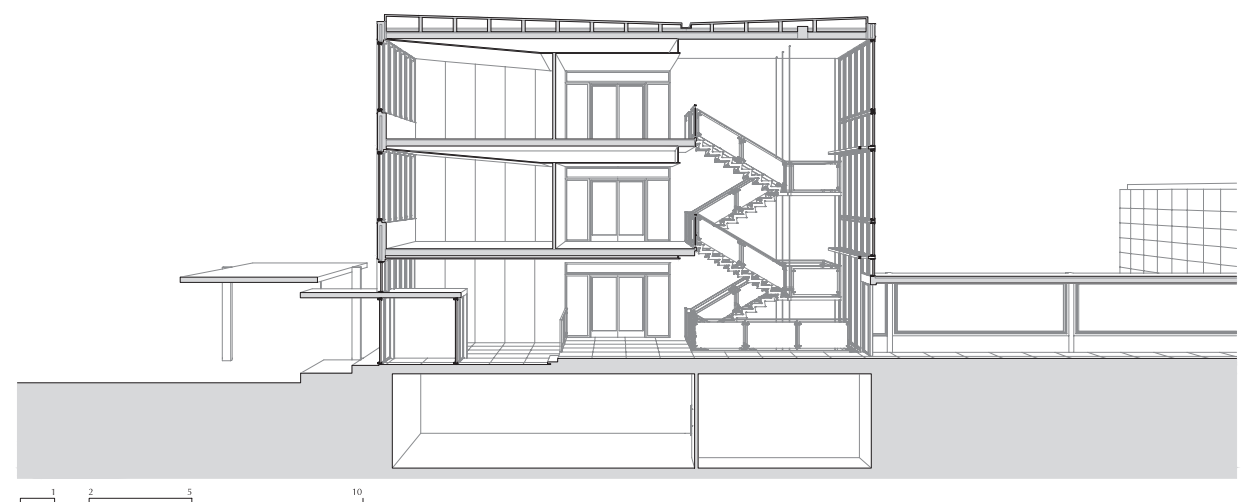

SECCIÓN FUGADA C-C' ESCALA GRÁFICA

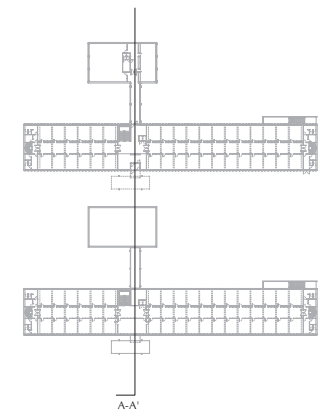

SECCIÓN FUGADA D-D' ESCALA GRÁFICA

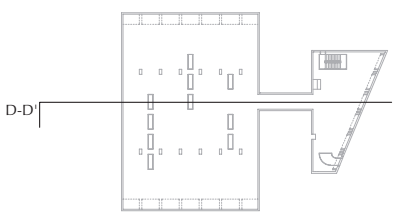

7. Sección fugada del Ayuntamiento de Rodovre por el eje central del vestíbulo mirando el triple espacio.

8. Sección fugada del Banco Nacional de Dinamarca por el eje central del vestíbulo proyectando el acceso principal.

9. Vista frontal desde el acceso mirando la escalera.

10. Vista frontal desde la escalera mirando el acceso.
En el caso del Banco Nacional de Dinamarca nos ha facilitado la elaboración de los documentos la obtención de dos fotografías que se ajustan a las premisas y en las que se destacan aspectos lumínicos que nos han ayudado a dar sentido al sistema constructivo de las escaleras (Figuras 11 y 12). La finalidad de la generación de los modelos tridimensionales y las perspectivas ha sido confirmar que tanto el diseño constructivo de estas dos escaleras como su posición están en relación directa a la composición general de sus respectivos vestíbulos; y a la voluntad de Arne Jacobsen de dotar a las escaleras de las mismas cualidades formales que tienen los elementos de acceso y los vestíbulos, generando un ambiente arquitectónico coherente.

\section{ASPECTOS TÉCNICOS DE LA ESCALERA DEL AYUNTAMIENTO}

\subsection{Forma y material (Figuras 13-19)}

La escalera del Ayuntamiento de Rodovre es de tipología lineal; está estructuralmente apoyada por un extremo y suspendida por
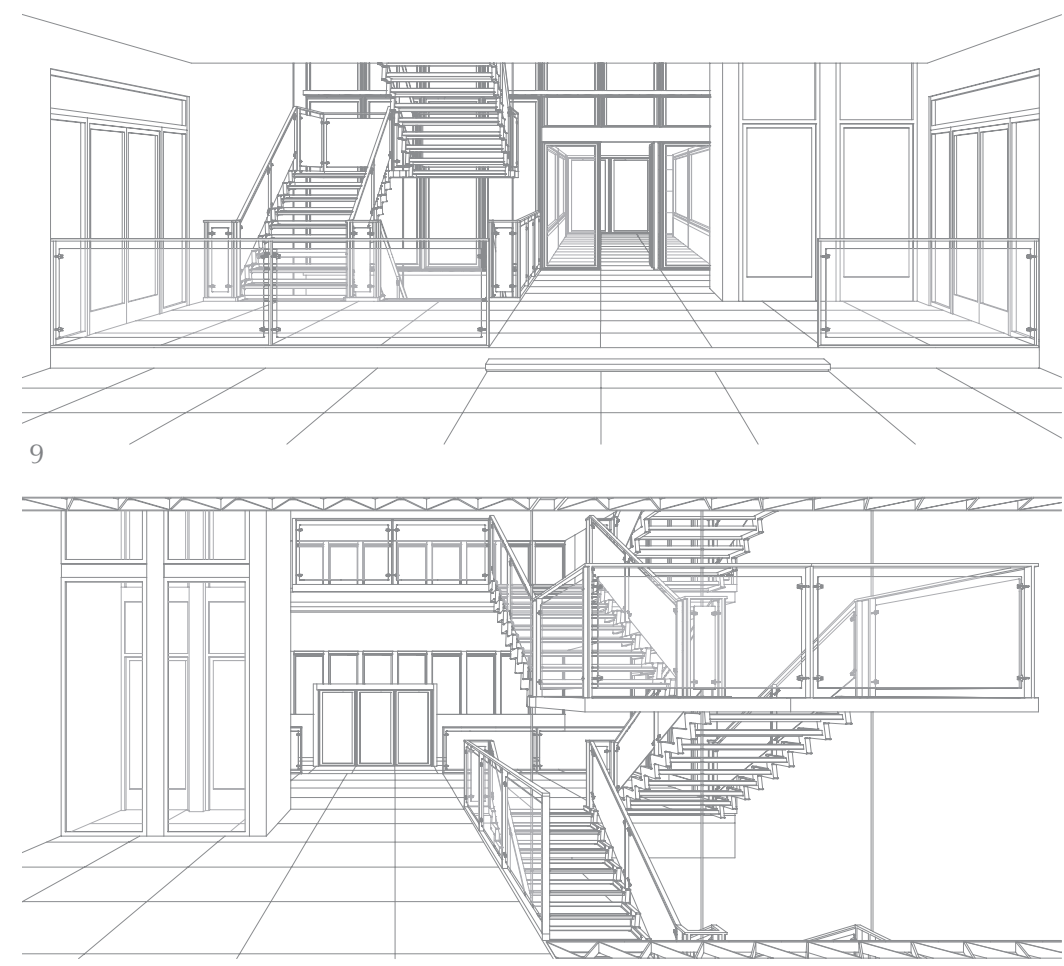

10 

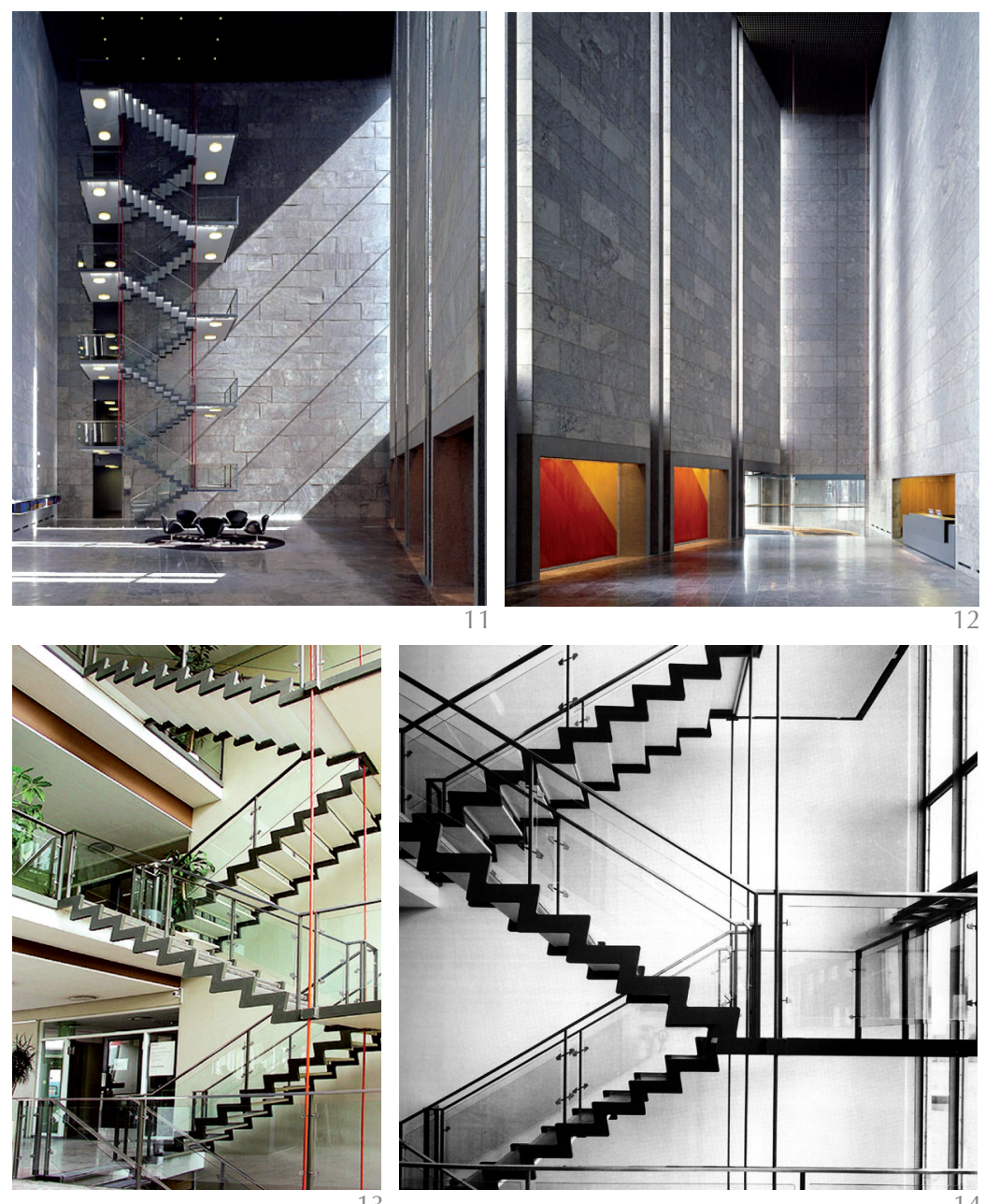

11. Vista frontal desde el acceso mirando la escalera. Arne Jacobsen, Edificios Públicos. 2G. 2005. Pág. 95.

12. Vista frontal desde la escalera mirando el acceso. Arne Jacobsen, Edificios Públicos. 2G. 2005. Pág. 87.

13. Fotografía lateral de la escalera. Aquí se observa el sitema estructural del conjunto.

14. Vista lateral de la escalera. Informes de la construcción. 1957. n. ${ }^{\circ}$ 91. Pág. 3.

15. Descripción bidimensional de la escalera del Ayuntamiento de Rodovre. Planta acceso y piso, sección longitudinal y transversal.

16. Detalle fotográfico de la escalera. Podemos observar el cajetín donde se regulan las deformaciones de las barras enroscadas. http:// en.wikipedia.org/wiki/File:Arne_ jacobsen, $\mathrm{r} \% \mathrm{C} 3 \% \mathrm{~B} 8 \mathrm{dov} r \mathrm{e}$

town_hall,_irwell_1952-19556.jpg
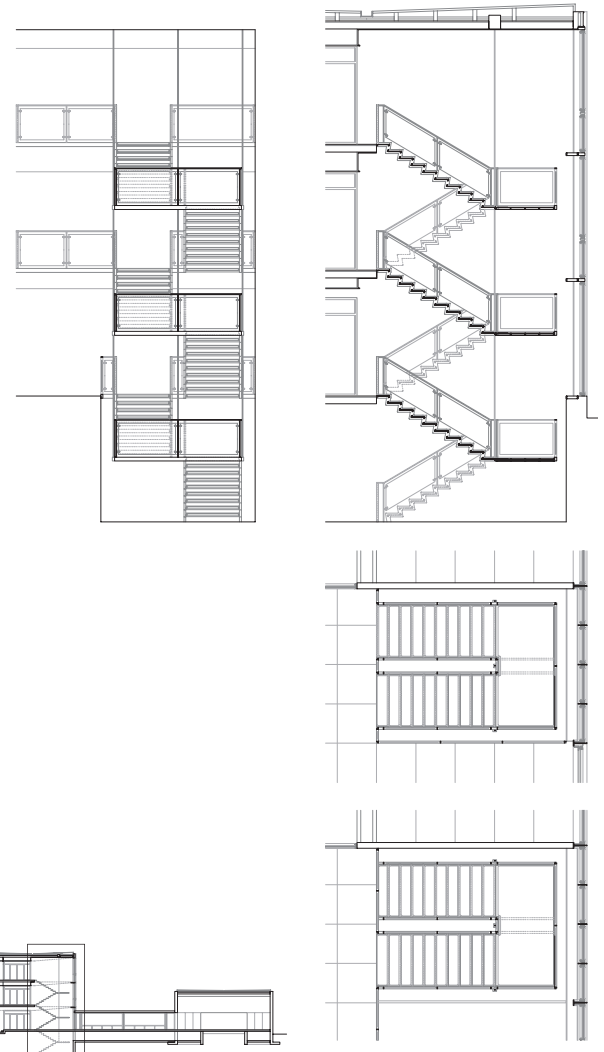

el extremo opuesto mediante tres tensores. El recorrido total de la escalera es de tres plantas de altura. Cada nivel, de altura 3,20 metros, es salvado mediante dos tramos lineales formados por 18 escalones.

Cada tramo lineal tiene una anchura libre de paso de 1,26 metros, equivalente a la anchura de cada peldaño. Cada escalón está formado por tres piezas: un acabado de goma rectangular para evitar que se pueda resbalar al subir o bajar por la escalera, una chapa de acero inoxidable con unos pliegues hacia arriba en su perímetro para evitar que se escape el pie hacia adelante, y unos perfiles metálicos de sección rectangular que van engastados a las zancas laterales y sobre los cuales se apoyan las dos primeras piezas. Hay que destacar que la chapa plegada queda separada 3 centímetros por banda sin contactar directamente con las zancas; así, deja el peldaño aireado y enfatiza el efecto de ligereza.

Las dos zancas quebradas por tramo están recortadas y pintadas de un gris oscuro y realizadas con perfiles tubulares de acero de sección rectangular de 50 milímetros de espesor. Éstas van definiendo el perfil y los límites de todo el conjunto, y sobre ellas se apoyan todos los peldaños, rellanos y barandillas.

Las barandillas, de altura 90 centímetros, están formadas por un travesaño superior metálico y de sección rectangular, unos montantes verticales en el punto medio de cada tramo y un vidrio. Este vidrio está delimitado por el travesaño superior y los montantes, y se encuentra anclado por cuatro piezas engastadas a los montantes verticales y que resisten a las torsiones.

Los tres tensores, de 24 milímetros de diámetro, están alineados perpendicularmente al final de cada tramo. Dos de ellos en el perímetro y el tercero en el centro, dejando el rellano en voladizo. Arne Jacobsen quiso remarcar la funcionalidad de cada uno de los elementos de la escalera dotándolos de un color; de esta, manera los tensores están pintados de color naranja, las zancas de color gris y los acabados generales de color blanco (2) (8) (11) (12).

\subsection{Estructura (Figuras 19 y 20)}

Para entender bien el comportamiento estructural de la escalera, primero se ha de entender el comportamiento estructural de la porción de edificio donde está suspendida. La estructura del edificio se resuelve mediante un sistema de dobles pilares situados en el corredor longitudinal del edificio y que se van repitiendo cada 4 metros.
DESCRIPCIÓN BIDIMENSIONAL

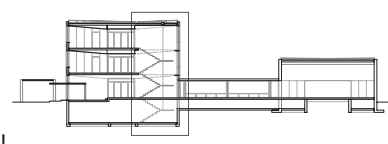

ESCALA GRÁFICA 
En cada par de pilares se apoya, perpendicularmente al sentido del corredor, una viga de sección variable que va perdiendo momento de inercia al acercarse a la fachada. Perpendicularmente a estas vigas se apoya un forjado de paneles prefabrica$\operatorname{dos}(2)(8)(11)(12)$.

En la zona del vestíbulo la luz estructural pasa de 4 a 10 metros, liberando este espacio de pilares. Esta excepción en la estructura del edificio hace que las dos vigas que delimitan las paredes del vestíbulo estén arriostradas perpendicularmente por otras vigas de sección rectangular, siendo de una de estas riostras de sección rectangular donde cuelga la escalera (Figura 20).

Como hemos dicho en la sección anterior, la escalera está suspendida por un lateral con tres tensores de 24 milímetros de diámetro que están repartidos linealmente al final de cada tramo, dejando el rellano en voladizo contrarrestando el momento de torsión de todo el sistema estructural. La deformación vertical de cada una de estas barras que terminan en rosca, se puede regular a través de un registro existente en cada uno de los rellanos. En el extremo opuesto, la escalera se engasta en cada nivel a una de las vigas de sección rectangular que rigidizan las vigas principales.

Las zancas laterales que actúan a modo de nervios, se encargan de distribuir todas las tensiones de la escalera a los tensores y a los puntos de engaste. En los tramos inclinados el sistema queda arriostrado horizontalmente por todos los peldaños y en los rellanos, por unos perfiles longitudinales en forma de "C" que están ocultos tras los acabados.

\subsection{Relación de materiales (Figura 19)}

A) Barra de acero de $24 \mathrm{~mm}$ de diámetro y pintada de naranja.

B) Vidrio endurecido de $10 \mathrm{~mm}$. de espesor.

C) Acabado de goma antideslizante de $1 \mathrm{~mm}$ de espesor y de color verde.

D) Plancha metálica de $5 \mathrm{~mm}$. de espesor.

E) Perfiles metálicos biselados 30×20 mm. de sección.

F) Anclajes de acero inoxidable atornillados y resistentes a la torsión.

G) Zancas perimetrales de acero inoxidable de 50x100 mm. de sección.

H) Perfiles metálicos de sección en forma de "C" 30x45 mm.

I) Montantes verticales de acero inoxidable de sección rectangular de 50×20 mm.

J) Barandilla de acero inoxidable de sección rectangular de 50×20 mm.
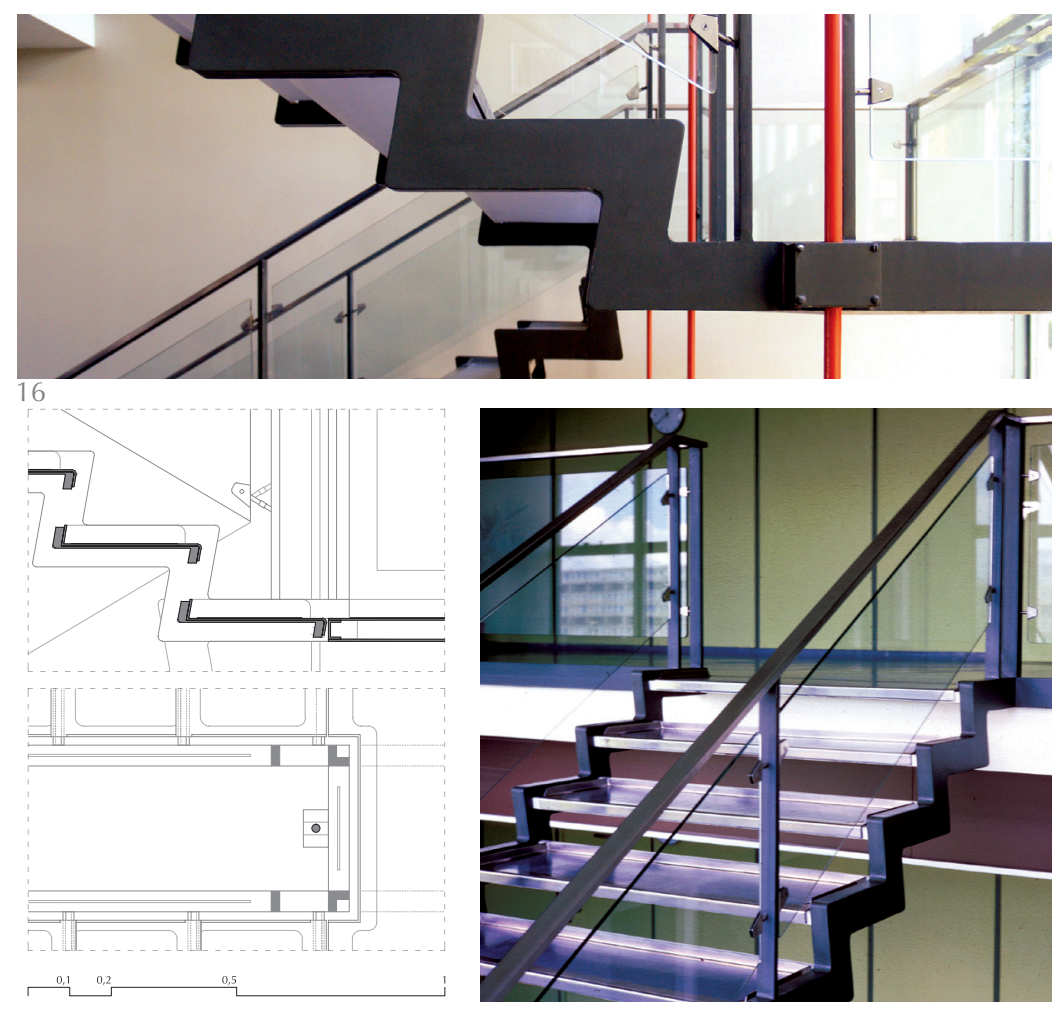

17

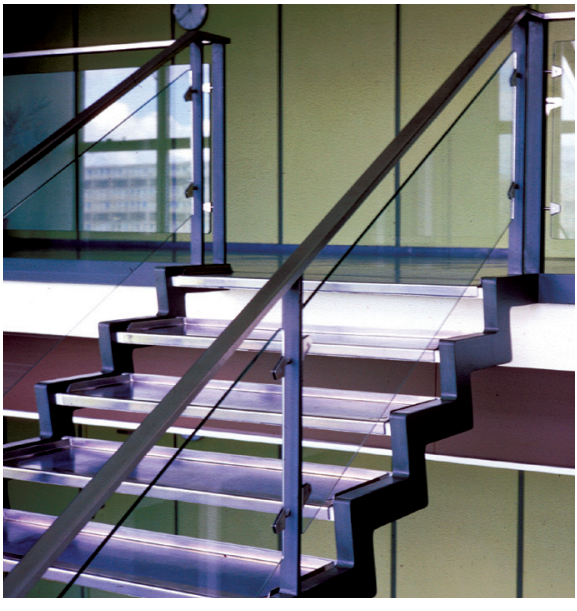

18
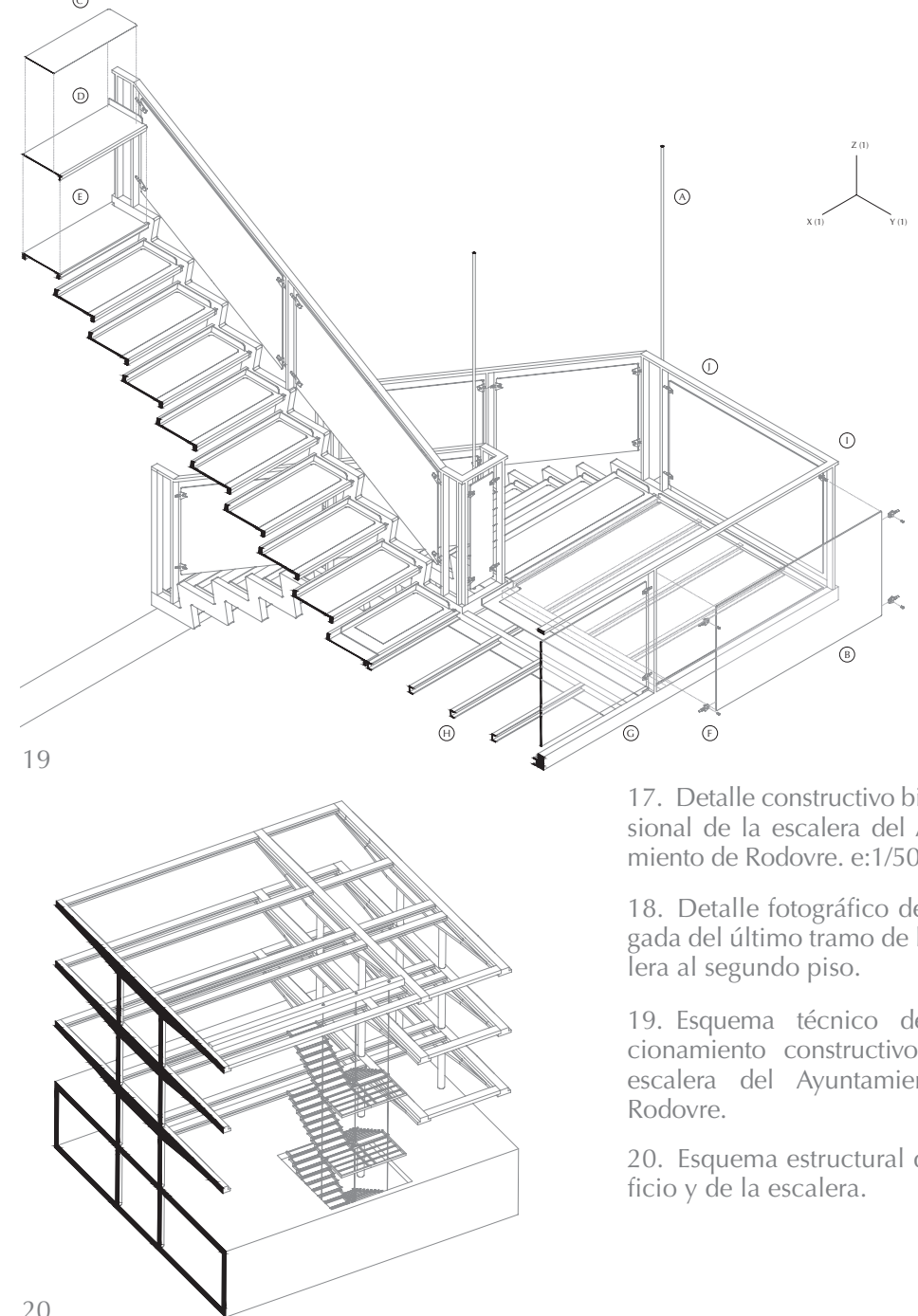

17. Detalle constructivo bidimensional de la escalera del Ayuntamiento de Rodovre. e:1/50.

18. Detalle fotográfico de la llegada del último tramo de la escalera al segundo piso.

19. Esquema técnico del funcionamiento constructivo de la escalera del Ayuntamiento de Rodovre.

20. Esquema estructural del edificio y de la escalera. 
21. Vista lateral de la escalera. Tahy, C. and Vinddum, K. Arne Jacobsen-København. Arkitektens Forlag/Danish Architectural Press, 2001. Portada.

22. Descripción bidimensional de la escalera del Banco Nacional de Dinamarca. Planta piso, sección longitudinal y transversal.

23. Detalle fotográfico de la escalera. Aquí podemos observar deformaciones de las barras roscadas. Nationalbankens bygning. 2003. Pág. 52. el cajetín donde se regulan las

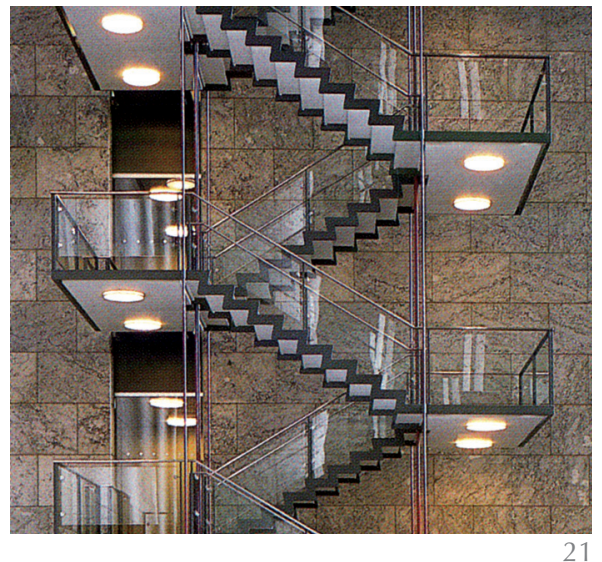

21
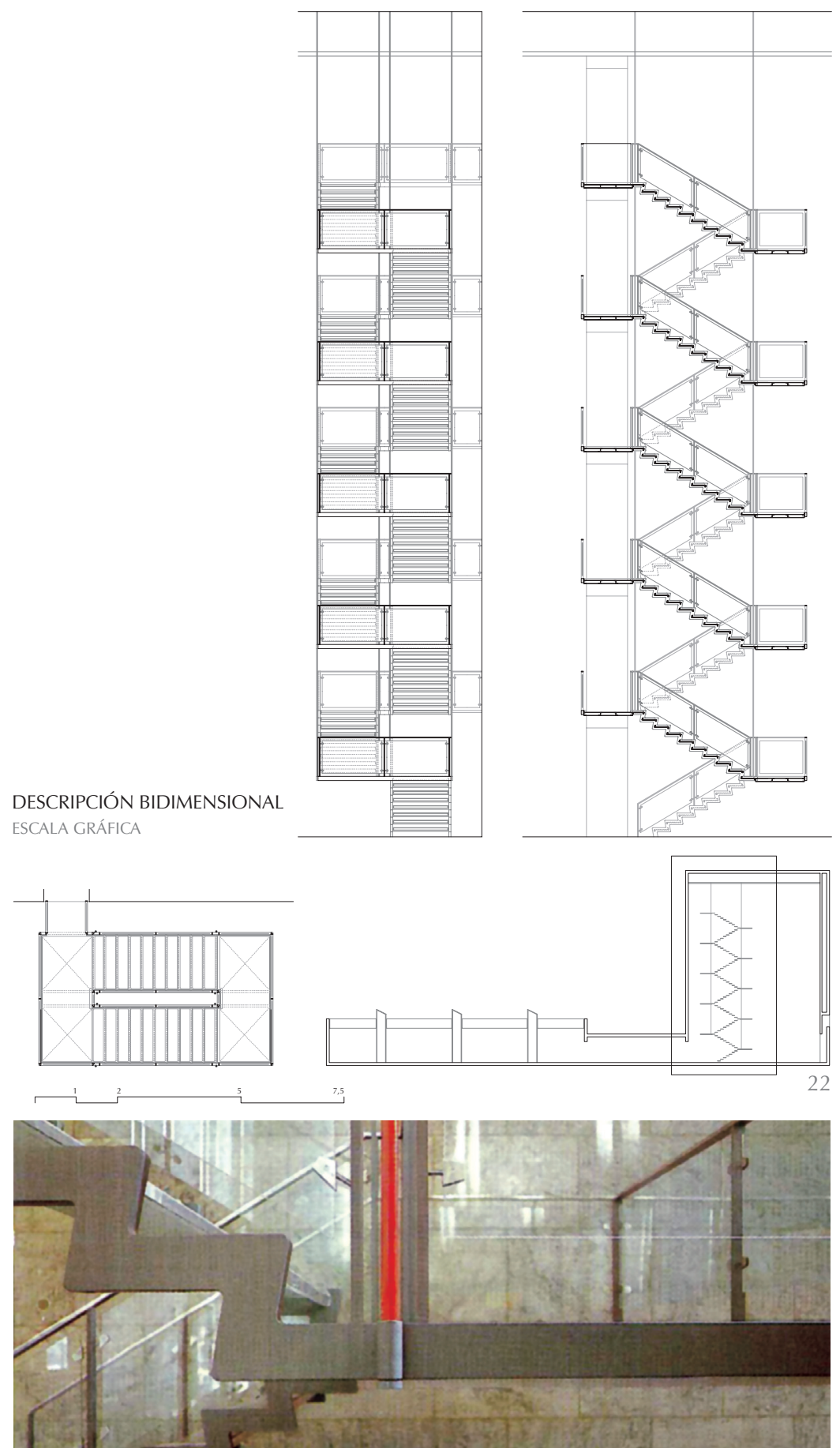

\section{ASPECTOS TÉCNICOS DE LA ESCALERA DEL BANCO NACIONAL}

8.1. Forma y material (Figuras 21-25)

La escalera del Banco Nacional de Dinamarca es de tipología lineal y está estructuralmente suspendida mediante ocho tensores. El recorrido total de la escalera es de cinco plantas de altura. Cada nivel, de altura 3 metros, es salvado mediante dos tramos lineales formados por 18 escalones, excepto la planta baja de altura 2,80 metros que está salvada mediante dos tramos lineales formados por 17 escalones.

Cada tramo lineal tiene una anchura libre de paso de 1,40 metros, equivalente a la anchura de cada peldaño. Cada escalón está formado por las mismas tres piezas que la escalera del ayuntamiento y con la misma estructura. Igualmente, en esta escalera la chapa plegada está separada 3 centímetros sin contacto con las zancas por los mismos motivos y efectos que en la escalera anterior.

Las dos zancas, por tramo, definen el conjunto y en ellas se apoyan los elementos de la misma manera que en la escalera anterior. Igualmente, las barandillas y sus elementos son similares a la escalera del Ayuntamiento.

Los ocho tensores, de 30 milímetros de diámetro, están simétricamente repartidos y alineados perpendicularmente al final de cada tramo. La mitad de ellos en el perímetro y la otra mitad en el centro, dejando los rellanos en voladizo. Deducimos que al menos uno de los cuatro tensores situados en el centro de la escalera es hueco y almacena cableado eléctrico, para dar corriente a los puntos de luz situados en cada rellano. Arne Jacobsen quiso remarcar la funcionalidad de cada uno de los elementos de la escalera dotándolos de un color, de esta manera los tensores están pintados de color rojo, las zancas de color gris y los acabados generales de color blanco (4) (11) (12) (14) (15) (16).

\subsection{Estructura (Figuras 25 y 26)}

Igual que en el Ayuntamiento, es necesario entender el comportamiento estructural de la porción de edificio donde la escalera se encuentra suspendida. La estructura del vestíbulo está pautada por seis módulos de fachada que se van encadenando linealmente cada 4,20 metros. En los extremos de cada módulo hay un pilar donde se apoya una viga de canto que cubre, de pared a pared, todo el techo del vestíbulo. Estas vigas tienen diferente longitud debido a la forma trapezoidal de este ámbito. 


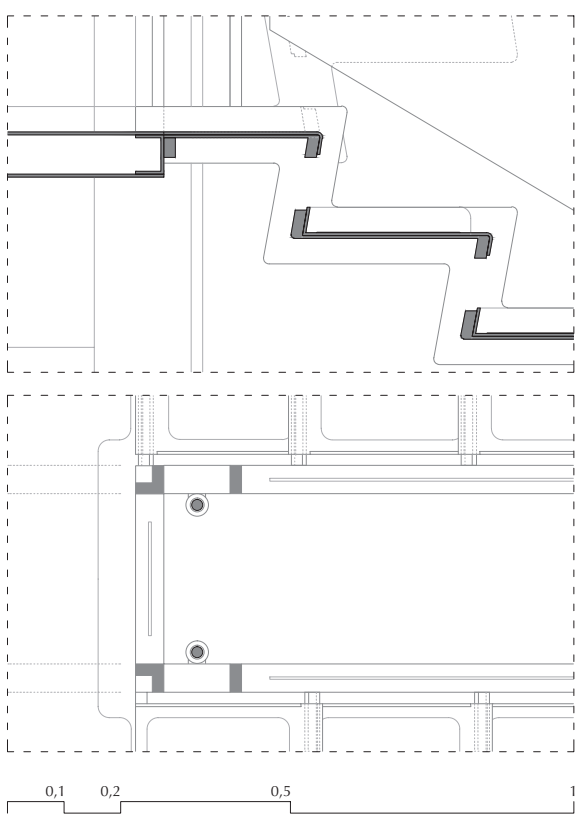

24

La escalera, al igual que el elemento de acceso, cuelga de unas vigas secundarias engastadas por ambos lados a las vigas principales. Así, mediante el orden de la fachada, queda justificado tanto la posición como el funcionamiento estructural del acceso y la escalera.

Como hemos dicho en la sección anterior, la escalera está completamente suspendida mediante ocho tensores de 30 milímetros de diámetro. Estas barras de acero están repartidas simétricamente $y$ alineadas al final de cada tramo, dejando los rellanos en voladizo contrarrestando el momento de torsión de todo el sistema estructural. La deformación vertical de cada una de estas barras, que terminan en rosca, se puede regular a través de un registro existente en cada uno de los rellanos.

Las zancas laterales, que actúan a modo de nervios, se encargan de distribuir todas las tensiones de la escalera a las ocho barras. En los tramos inclinados el sistema queda arriostrado horizontalmente por todos los peldaños, y los rellanos toman rigidez con dos cruces de San Andrés formadas con perfiles metálicos en forma de "Z" que quedan ocultas tras los acabados metálicos.

La escalera está separada 75 centímetros del piso al que ha de conectar, esto se resuelve mediante una pasarela metálica de mínima sección. Esta pasarela queda apoyada por un extremo a los rellanos de la propia escalera y por el otro extremo a los forjados del edificio. Precisamos que este elemento conector no colabora estructuralmente con la escalera (4) (11) (12) (14) (15) (16).

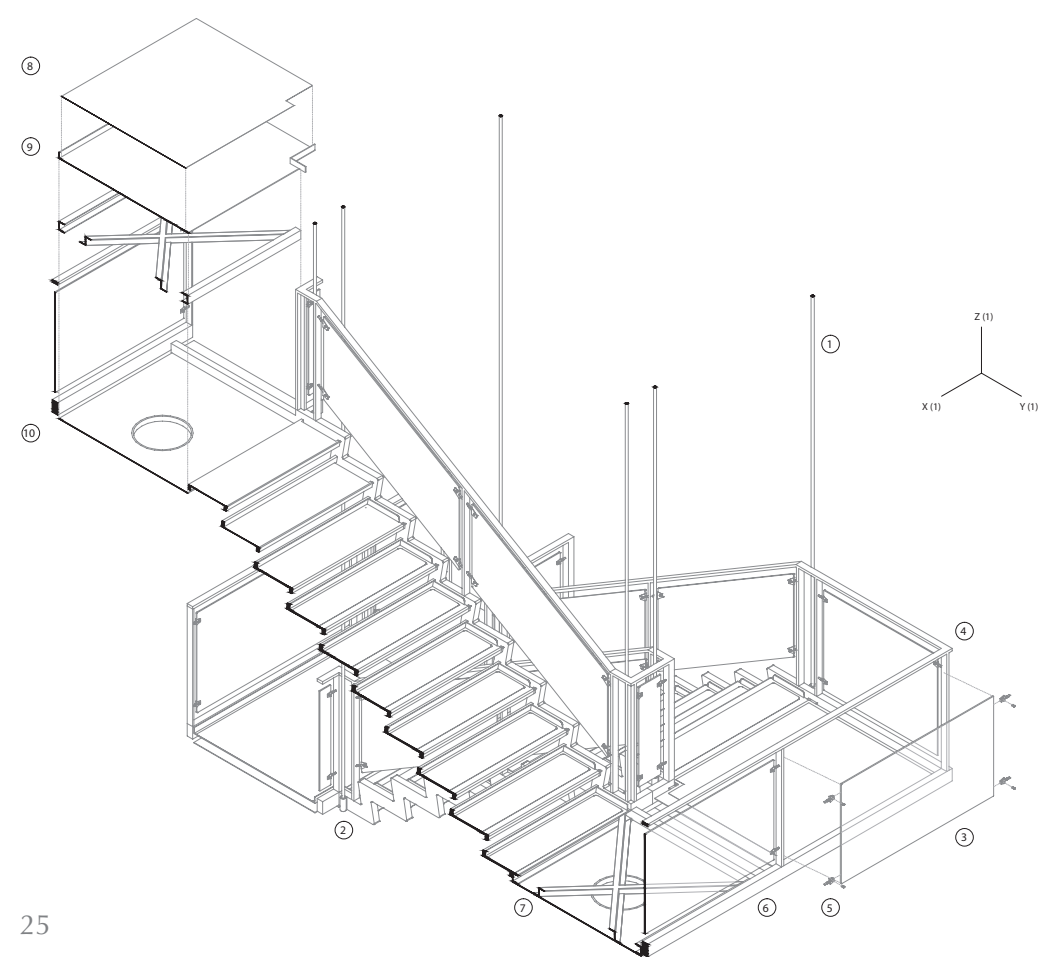

8.3. Relación de materiales (Figura 25)

1) Barra de acero de $30 \mathrm{~mm}$ de sección, pintada de rojo.

2) Pieza de registro regulable de las barras de acero.

3) Vidrio endurecido de $10 \mathrm{~mm}$ de espesor. 4) Barandilla de acero inoxidable de sección rectangular de 50×20 mm.

5) Anclajes de acero inoxidable atornillados y resistentes a la torsión.

6) Zancas perimetrales de acero inoxidable de 50×100 mm de sección.

7) Perfiles metálicos de sección en forma de "Z" 100x70 mm.

8) Acabado de goma antideslizante de $1 \mathrm{~mm}$ de espesor y color verde.

9) Plancha metálica de $5 \mathrm{~mm}$ de espesor.

10) Iluminación empotrada de forma circular de 40 centímetros de diámetro.

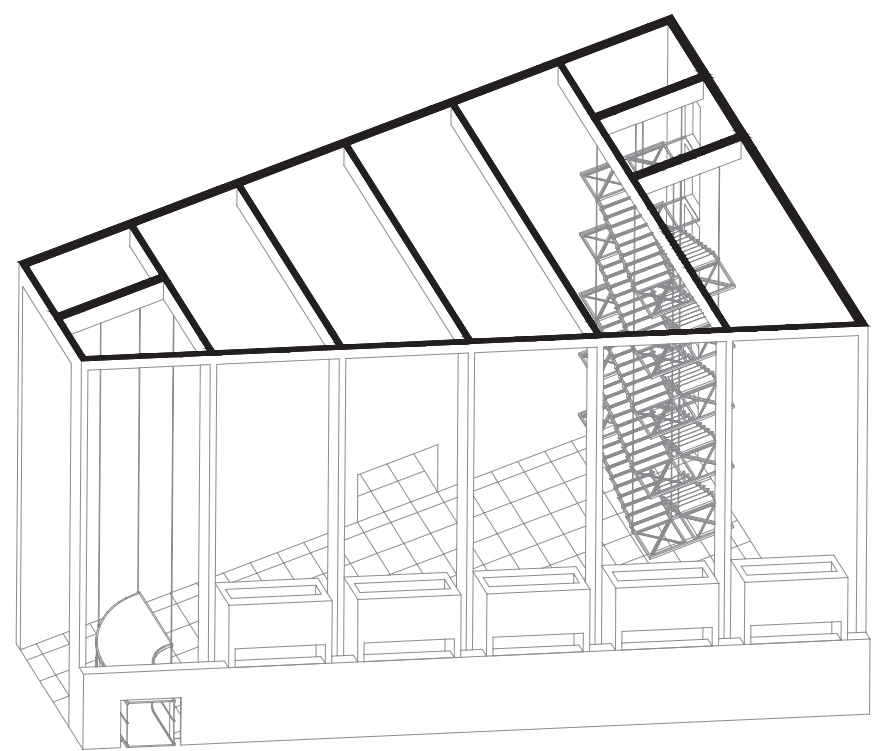




\section{CONCLUSIONES}

En el presente trabajo reflejamos con fidelidad la escasa documentación original obtenida. A partir de la misma, elaboramos un modelo tridimensional y presentamos nueva documentación con la que se pueden destacar y contrastar los diferentes elementos de estudio.

Además, con este estudio cualquier arquitecto interesado en las escaleras de Arne Jacobsen puede obtener todos los datos sobre las mismas; datos que por diferentes motivos no se encontraban, hasta el presente artículo, a disposición pública.

Y además de otras cuestiones que cualquier arquitecto puede estudiar a partir del trabajo elaborado, podemos concluir que:

- Estas dos escaleras estudiadas y presentadas, que temporalmente se construyeron con siete años de diferencia, se rigen con los mismos trazos constructivos y formales dentro de dos vestíbulos aparentemente distintos.

- Enmarcándolas en su contexto histórico observamos que las primeras escaleras colgadas se remontan a principios del siglo pasado. Arquitectos punteros como Rudolf Schindler o Richard Neutra empezaron a colocar escaleras suspendidas lineales en viviendas unifamiliares. Estos primeros ensayos consistían en suspender por un extremo cada uno de los peldaños y engastarlos por el otro lado. Las escaleras suspendidas empezaron a despuntar en 1935 cuando el arquitecto Frank Lloyd Wright diseñó una escalera lineal colgada en la Casa de la Cascada. El sistema constructivo de esta escalera era parcialmente similar al sistema planteado por Schindler y Neutra, ya que consistía en colgar íntegramente cada uno de los peldaños de tal manera que cada barra atravesara dos peldaños para contrarrestar las vibraciones y el momento de torsión. En los siguientes años, el sistema estructural en este tipo de escaleras se sofisticó. El progreso en la cons- trucción con materiales tan novedosos como el acero permitieron aplicar nuevas fórmulas estructurales en el diseño de las escaleras. Arne Jacobsen fue uno de los primeros arquitectos que planteó colgar completamente toda la escalera gracias a un sistema de zancas dentadas, en el caso de escaleras lineales, y un sistema de chapa de plegada, en el caso de escaleras helicoidales. En el diseño de las escaleras de estudio de este artículo observamos que a nivel estructural hay un cambio notable. La escalera de Rodovre está parcialmente suspendida y la escalera del Banco Nacional de Dinamarca cuelga completamente, realzando así las cualidades arquitectónicas de sus vestíbulos correspondientes.

- A lo largo de toda la obra arquitectónica de Arne Jacobsen encontramos tres escaleras suspendidas. En los respectivos proyectos donde se localizan estas tres escaleras (Ayuntamiento de Rodovre, Banco Nacional de Dinamarca y Hotel Royal SAS), existe un elemento de acceso que también está suspendido. Con esto, remarcamos que el diseño de la escalera también repercute a nivel compositivo en el diseño del vestíbulo, y que la decisión de colgar las escaleras se hace en consonancia con otro elemento de mismo espacio, destacando así la dualidad como motivo y orden de proyecto. La tercera escalera aludida, del Hotel Royal SAS en la ciudad de Copenhague (1955), merece un estudio bien elaborado y aparte de las dos escaleras presentadas en este trabajo. Esto es así a causa de las diferencias de diseño, estructura y composición.

- Después de una detallada búsqueda bibliográfica, podemos afirmar que el presente artículo es el primer documento que detalla públicamente el análisis funcional, formal y estructural de cada una de las escaleras. Así, con este trabajo, ponemos al alcance de arquitectos, o profesionales interesados de cualquier rama, una nueva fuente de ideas sobre la técnica y filosofía del excepcional autor Arne Jacobsen.

\section{REFERENCIAS}

(1) Brundtland, G. (1987). Our common future. Report of the World Commission on Environment and Development. Transmitted to the General Assembly as an Annex to document A/42/427 - Development and International Co-operation: Environment.

(2) Oteiza, I., Alonso, C. (2008, 24 de mayo). Análisis y revisión de herramientas para evaluación de la sostenibilidad de la construcción. Actas de las II Jornadas de Investigación en Construcción, pp. 1149-1166. Madrid.

(3) Real Decreto 314/2006, de 17 de marzo, por el que se aprueba el Código Técnico de la Edificación.

(4) Real Decreto 47/2007, de 19 de enero, por el que se aprueba el Procedimiento básico para la certificación de eficiencia energética de edificios de nueva construcción. 
(5) Real Decreto 105/2008, de 1 de febrero, por el que se regula la producción y gestión de los residuos de construcción y demolición.

(6) Estrategia temática sobre el uso sostenible de los recursos naturales. Comunicación de la Comisión de 21 de diciembre de 2005 - COM (2005) 670.

(7) González, M.J. (2004, 27 de febrero). El papel de los materiales de Construcción en la arquitectura sostenible. Actas de las III Jornadas abulenses de energías renovables y medio ambiente. Taller de arquitectura de bajo impacto ambiental. Ávila.

(8) Castro-Lacouture, D., Sefair, J., Flórez, L., Medaglia, A. (2009). Optimization model for the selection of materials using a LEED-based green building rating system in Colombia. Building and Environment, 44(6): 1162-1170. doi: 10.1016/j.buildenv.2008.08.009.

(9) Ferrer, I. (2007). Contribución metodológica en técnicas de diseñar para fabricación. (Tesis doctoral). Universidad de Girona.

(10) López-Mesa, B., Gallego, T., Mulet, E., Pitarch, A., Tomás, A. (2007, 28-31 de agosto) Exploring the need for an evaluation model to assist in the eco-efficient selection of building systems. Proceedings of the 16th International Conference on Engineering Design 2007 (ICED07). París.

(11) ICARO del Colegio Territorial de Arquitectura de Valencia. (2003). 100 Materiales Sostenibles.

(12) Cebrián-Tarrasón, D., Garraín, D., París, A., Vidal, R. (2009, 8-10 de julio). ACV libre: la Utilización del ELCD en la Fase de Diseño. Actas del XIII Congreso de Ingeniería de Proyectos (AEIPRO). Badajoz.

(13) Haapio, A., Viitaniemi, P. (2008). A critical review of building environmental assessment tools. Environmental Impact Assessment Review, 28(7): 469-482. doi: 10.1016/j. eiar.2008.01.002.

(14) ANNEX 31, International Energy Agency. Retrieved June 16, 2010 from the world wide web: http://www.uni-weimar.de/scc/PRO/survey.html.

(15) Eldridge, C. (2002). Lcaid ${ }^{\mathrm{TM}}$ Software: Measuring Environmental Performance Of Buildings. NSW Department of Public Works and Services, Sydney, Australia.

(16) Forsberg, A., Malmborg, F. (2004). Tools for environmental assessment of the built environment. Building and Environment, 39(2): 223-228. doi: 10.1016/j.buildenv.2003.09.004.

(17) Fowler, K., Rauch, E. (2006): Sustainable Building Rating Systems Summary. Completed by the Pacific Northwest National Laboratory for the U.S. Department of Energy, U.S.

(18) Kohler, N.; Wagnwe, A.; Luetzkendorf, T.; König, H.: "Life Cycle assessment of passive buildings with LEGEP - a LCA-tool from Germany". 2005 World Sustainable Building Conference, Tokyo, 27-29 September 2005.

(19) Lippiatt, B., Boyles, A. (2001). Using Bees to select Cost-Effective Green Products, International Journal of LCA, 6(2): 76-80.

(20) Macías, M., García Navarro, J. (2010). Metodología y herramienta VERDE para la evaluación de la sostenibilidad en edificios. Informes de la Construcción, 62(517): 87-100 doi: 10.3989/ic.08.056.

(21) Seo, S., Tucker, S., Ambrose, M., Mitchell, P., Wang, C-H. (2005). Technical Evaluation of Environmental Assessment Rating Tools. Forest and Wood Products Research and Development Corporation. Australia.

(22) Yuan, W. (2005). Comparison of two sustainable building assessment tools applied to Holmen project in Stockholm. (Masther thesis). Royal Institute of Technology, Stockholm, Sweden.

(23) Athena Institute. LCA model. Retrieved June 16, 2010 from the World Wide Web: http:// www.athenasmi.ca

(24) Hammond, G. P., Craig I. J. (2006). Inventory of Carbon and Energy (ICE), Sustainable Energy Research Team (SERT), University of Bath. Retrieved from the world wide web on 10 June 2010 from: http://www.bath.ac.uk/mech-eng/sert/embodied/

(25) Howarth, G., Hadfield, M. (2006). A sustainable product design model. Materials and Design, 27(10): 1128-1133. doi: 10.1016/j.matdes.2005.03.016.

(26) Malin, N. (2005). Life cycle assessment for whole buildings: seeking the holy grail. Building Design and Construction, pp. 6-11.

(27) Ruá, M.J., Vives, L., Civera, V., López-Mesa, B. (2010, 15-16 de febrero). Aproximación al cálculo de la eficiencia energética de fachadas ventiladas y su impacto ambiental. Actas del XI Congreso mundial de la calidad del azulejo y del pavimento cerámico QUALICER 2010, Castellón. 